The Journal of Rheumatology 2021;48:3

doi: $10.3899 /$ jrheum. 201218

First Release October 152020

\section{Dr. Elfishawi, et al reply}

To the Editor:

We thank Huang and colleagues ${ }^{1}$ for their interest in our study on the changes in the presentation of incident gout and the risk of subsequent flare ${ }^{1}$. We reported changes over time in gout presentation with podagra becoming less frequent, whereas hyperuricemia and chronic kidney disease were predictors of future flares ${ }^{2}$.

Our group previously reported the risk of in-hospital flares in patients with incident gout, where we reported a 10 -fold increase in gout flares during hospitalization ${ }^{3}$. In that analysis, discontinuation of urate-lowering therapy (ULT) was not significantly associated with increased risk of in-hospital flare (OR 0.86; 95\% CI 0.11-6.83).

Huang and colleagues have reported an increased risk of flares in the postdischarge period when ULT was discontinued in their patient population ${ }^{1}$. These findings augment our prior study of hospitalized patients with gout in showing that not only is the risk of flares increased during the hospital stay, but the increased risk may extend to the posthospitalization period and up to 3 months after discharge. Increasing awareness about the effect of discontinuing ULT among general practitioners and internists is of great importance to avoid preventable flares in patients with gout ${ }^{4}$.

Mohanad Mahmoud Elfishawi ${ }^{1}$, MBBCh, MSc

Cynthia S. Crowson ${ }^{1,2}$ (D) $\mathrm{PhD}$

Eric L. Matteson ${ }^{1,3}$, MD, MPH

Tim Bongartz ${ }^{4}, \mathrm{MD}, \mathrm{MS}$

${ }^{1}$ Division of Rheumatology, Mayo Clinic College of Medicine,

Rochester, Minnesota;

${ }^{2}$ Division of Biomedical Statistics and Informatics, Health Sciences

Research, Mayo Clinic College of Medicine, Rochester, Minnesota;

${ }^{3}$ Division of Epidemiology, Department of Health Sciences Research,

Mayo Clinic College of Medicine, Rochester, Minnesota;

${ }^{4}$ Department of Emergency Medicine, Vanderbilt Medical Center,

Nashville, Tennessee, USA.
This work was made possible using the resources of the Rochester Epidemiology Project, which is supported by the US National Institute on Aging of the National Institutes of Health (NIH) under Award Number R01AG034676 and Clinical and Translational Science Awards Grant Number UL1 TR000135 from the National Center for Advancing Translational Sciences, a component of the NIH. The content is solely the responsibility of the authors and does not necessarily represent the official views of the NIH.

Address correspondence to Dr. M.M. Elfishawi, Mayo Clinic, Division of Rheumatology, 200 1st St. SW, Rochester, Minnesota 55905-0002, USA. Email: Elfishawi.Mohanad@mayo.edu.

\section{REFERENCES}

1. Huang IJ, Bays AM, Liew JW. Frequency of allopurinol dose reduction in hospitalized patients with gout flares. J Rheumatol 2021;48:467-8.

2. Elfishawi MM, Zleik N, Kvrgic Z, Michet CJ, Crowson CS, Matteson EL, et al. Changes in the presentation of incident gout and the risk of subsequent flares: a population-based study over 20 years. J Rheumatol 2020;47:613-8.

3. Zleik N, Elfishawi MM, Kvrgic Z, Michet CJ Jr, Crowson CS, Matteson EL, et al. Hospitalization increases the risk of acute arthritic flares in gout: a population-based study over 2 decades. J Rheumatol 2018;45:1188-91.

4. Nitichaikulvatana P, Upchurch KS, Harrold LR. Impact of deficits in gout care on hospitalizations. J Clin Rheumatol 2011;17:389-91. 